\title{
SIFAT MEKANIK ELEKTRODA BATANG ARDE AKIBAT KOROSI PADA PEMBUMIAN TANAH BERPASIR
}

\author{
Muhamad Iqbal Achmad \\ Program Studi Teknik Mesin, Fakultas Teknik \\ Universitas Dayanu Ikhsanuddin \\ E-mail: iqballatengko@gmail.com
}

\begin{abstract}
Abstrak
Penelitian ini bertujuan untuk mengetahui sfat mekanis elektroda batang arde akibat korosi pada pembumian tanah pasir pembumian. Penelitian ini menggunakan metode eksperimental yang mana spesimen dipancangkan kedalam tanah (proses pembumian) pada kedalaman 1 meter dengan waktu \pm 30 hari dan specimen uji dibuat di Laboratorium Teknik Mesin Universitas Dayanu Ikhsanuddin serta diuji pada Laboratorium Metalurgi Teknik Mesin Fakultas Teknik Universitas Hasanuddin Makassar. Hasil penelitian yaitu struktur mikro elektroda batang arde terdiri dari fasa perlit dan fasa ferit. Fasa perlit ditunjukan dengan warna gelap dan fasa ferit ditunjukan dengan warna terang. Setelah melalui proses pembumian fasa ferit yang berwarna terang lebih mendominasi pada setiap sampelnya di banding dengan fase perlit yang berwarna gelap. Fasa ferit yang bersifat lunak, sehingga mempengaruhi tingkat kekerasan pada elektroda batang arde. Setiap sampel specimen yang melalui proses pembumian pada lokasi tanah pasir terjadi penurunan nilai kekerasan. Nilai Uji Kekerasan Brinell pada lokasi tanah berpasir sebesar $129,77 \mathrm{kgf} / \mathrm{mm}^{2}$. Tingkat korosi yang tinggi pada suatu lokasi sangat mempengaruhi tingkat kekerasan elektroda batang arde, semakin tinggi tingkat korosinya maka akan semakin besar penurunan nilai kekerasannya.
\end{abstract}

Kata kunci: Korosi, HBN (Brinell), dan Metalografi.

\begin{abstract}
This study aims to determine the mechanical sfat grounding rod electrodes due to corrosion of the earthing earthing sandy soil. This research uses experimental methods in which specimens anchored into the ground (the earth) at a depth of 1 meter with a time of \pm 30 days and test specimens were made at the Laboratory of Mechanical Engineering University Dayanu Ikhsanuddin and tested at the Metallurgical Laboratory Faculty of Engineering, University of Hasanuddin Makassar. The results of research that stems grounding electrode microstructure consisting of ferrite phase and phase pearlite. Pearlite phase is shown with a dark color and the ferrite phase is shown with bright colors. After going through the process of ferrite phase earthing brightly colored dominates in each sample compared with perlite dark phase. Which is soft ferrite phase, thereby affecting the level of violence on the ground rod electrodes. Each sample specimen through the process of grounding on sand soil locations are impaired violence. Values Brinell Hardness Test on the location of the sandy soil of $129.77 \mathrm{kgf} / \mathrm{mm} 2$. The corrosion rates are high on a location strongly influence the level of violence grounding rod electrodes, the higher the level of corrosion, the greater the decrease in the value of its hardness.
\end{abstract}

Keywords: Corrosion, HBN (Brinell), and Metallography. 


\section{SANG PENCERAH}

Volume 2, Nomor 2, Agustus 2016, ISSN 2460-5697, H1m. 39-44

Muhamad Iqbal Achmad: Sifat Mekanik Elektroda Batang Arde ...

\section{Pendahuluan}

Lonjakan listrik sering terjadi pada gedung perkantoran atau perumahan yang di akibatkan karena adanya sambaran petir dan menimbulkan kerusakan pada peralatan-peralatan yang menggunakan sumber listrik sebagai sumber tenaga, seperti komputer, TV, kulkas dan lain-lain. Dalam mengantisipasi hal tersebut di atas, setiap bangunan atau perumahan diharuskan menggunakan system grounding, pentanahan atau pembumian dengan menggunakan batang arde sebagai elektroda penyalur arus kedalam tanah. Terkadang elektroda batang arde tersebut tidak sesuai dengan umur yang kita inginkan, salah satu faktornya adalah ketahanan pada logam yang digunakan. Elektroda batang Arde yang digunakan, yaitu pipa besi, baja profil, tembaga atau batang logam lainnya yang dipancangkan ke dalam tanah dan biasanya pada bahan logam tersebut telah dilapisi dengan lapisan tembaga.

Telah diketahui bersama bahwa logam, khususnya besi dan baja bila ditanam dalam tanah maka akan terjadi pengaratan (korosif). Korosi atau karat merupakan fenomena alamiah yang biasa terjadi pada material logam,dimana korosi merupakan proses kerusakan material karena reaksi kimia atau elektrokimia dengan lingkungannya. Sama halnya tulang manusia yang menjadi rapuh karna penuaan, logam yang korosi juga menjadi rapuh akibat proses pengkaratan. Oleh sebab itu, korosi tidak dapat dicegah atau dihentikan sama sekali. Korosi hanya bisa dikendalikan atau diperlambat lajunya sehingga memperlambat proses perusakannya. Menyadari keadaan ini, pengendalian korosi dan penanggulangannya perlu dilakukan dengan lebih efektif.

Banyak cara dapat dilakukan untuk meningkatkan sifat tahan karat dari baja karbon rendah dan salah satu alternatif yang dapat dilakukan adalah dengan melakukan proses pelapisan listrik pada baja dengan menggunakan bahan pelapis tahan karat seperti nikel, tembaga, seng, krom, dan lainlain.

Tabel 1 Harga-harga Tahanan Jenis Tanah (P) dari Berbagai Jenis Tanah.

\begin{tabular}{lc}
\hline \multicolumn{1}{c}{ Jenis Tanah } & $\begin{array}{c}\text { Tahanan Jenis Tanah } \\
\text { (ohm.meter ) }\end{array}$ \\
\hline Tanah dan pasir yang & $5-6$ \\
mengandung air garam & 30 \\
Rawa & 100 \\
Tanah liat & 200 \\
Pasir Basah & 1000 \\
Batu-batu kerikil basah & 1000 \\
Pasir dan batu krikil kering & 3000 \\
Batu & \\
\hline
\end{tabular}

Sumber: Nilai resistivitas tanah menurut pasal 3.18-1 PUIL2000

Tabel 2 Tahanan Jenis Tanah dan Daya Korosinya

\begin{tabular}{ll}
\hline \multicolumn{1}{c}{$\begin{array}{c}\text { Tahanan Jenis Tanah } \\
\text { (ohm.meter) }\end{array}$} & \multicolumn{1}{c}{ Daya Korosi } \\
\hline $0-25$ & Tinggi \\
$25-50$ & Menengah \\
$50-100$ & Rendah \\
$>100$ & Sangat rendah \\
\hline Sumber:http://digilib.unimus.ac.id/files/disk1/11 \\
\cline { 2 - 2 } & $\underline{\text { 9/jtptunimus-gdl-muhamatyas-5924-}}$ \\
& $\underline{\text { 3-babii.pdf }}$
\end{tabular}

Pemilihan bahan logam untuk penggunaan elektroda batang Arde selain tahan terhadap korosi juga mempunyai sifat kekerasan dan kekuatan pada logam tersebut. Hubungan kekerasan sebanding dengan kekuatan logam dimana kekerasan suatu logam akan meningkat maka kekuatan logam tersebut juga cendrung meningkat, namun nilai kekerasan ini berbanding terbalik dengan keuletan dari logam. Meskipun logam keras dipandang lebih kuat dari pada logam lunak, namun yang perlu diperhatikan adalah bahwa tingkat kekerasan bahan yang tinggi belum menjamin memiliki kekuatan (ketahanan) untuk menerima beban. Oleh karena itu Penelitian ini bertujuan untuk mengetahui sfat mekanis elektroda batang arde akibat 


\section{SANG PENCERAH}

Volume 2, Nomor 2, Agustus 2016, ISSN 2460-5697, H1m. 39-44

Muhamad Iqbal Achmad: Sifat Mekanik Elektroda Batang Arde ...

korosi pada pembumian tanah pasir pembumian. Berdasarkan uraian di atas, fokus penelitian ini adalah bagaimana sifat mekanik elektroda batang Arde akibat korosi pada pembumian tanah berpasir?

Tujuan penelitian ini adalah untuk mengetahui sifat mekanik elektroda batang Arde akibat korosi pada pembumian tanah berpasir.

\section{Metode Penelitian}

\section{Lokasi dan Rancangan Penelitian}

Penelitian dilaksanakan secara eksperimental di laboratorium Metalurgi Jurusan Teknik Mesin Univesitas Hasanuddin Makassar untuk pengujian kekerasan Brinell dan pengujian mikrostruktur serta dipesisiran pantai Kota Baubau untuk pembumian elektroda batang Arde. Bahan yang digunakan dalam penelitian ini adalah elektoda batang arde yang biasa dijual dipasaran kota baubau dengan diameter $8 \mathrm{~mm}$. dan proses pembumian pada kedalaman 1 meter (dipancangkan kedalam tanah pasir) dengan waktu \pm 30 hari. Pembuatan spesimen untuk material uji dilakukan di Laboratorium Teknik Mesin Universitas Dayanu Ikhsanuddin BauBau.

\section{Metode Pengambilan Data Kekerasan Brinell}

Uji lekukan yang pertama kali banyak digunakan serta disusun pembakuannya adalah metode yang diajukan oleh J.A. Brinell pada tahun 1900. Uji kekerasan Brinell berupa pembentukan lekukan pada permukaan logam dengan memakai bola baja berdiameter $10 \mathrm{~mm}$ dan diberi beban $3000 \mathrm{~kg}$. Untuk logam lunak, beban dikurangi hingga tinggal $500 \mathrm{~kg}$, untuk menghindarkan jejak yang dalam, dan untuk bahan yang sangat keras, digunakan paduan karbida tungsten, untuk memperkecil terjadinya distorsi indentor.
Beban diterapkan selama selang waktu tertentu, biasanya 30 detik, dan diameter lekukan diukur dengan mikroskop daya rendah, setelah beban tersebut dihilangkan. Kemudian dicari harga rata-rata dari 2 buah pengukuran diameter pada jejak yang berarah tegak lurus, permukaan dimana lekukan akan dibuat harus relatif halus, bebas dari debu atau kerak. Angka kekerasan Brinell (BHN) dinyatakan sebagai beban $\mathrm{P}$ dibagi luas permukaan lekuakan. Rumus untuk angka kekerasan tersebut sebagai berikut.

$$
\mathrm{BHN}=\frac{2 \mathrm{P}}{\pi \mathrm{D}\left[\left(\mathrm{D}-\sqrt{\left(\mathrm{D}^{2}-d^{2}\right)}\right]\right.}
$$

Dimana :

$\mathrm{BHN}=$ Nilai kekerasan Brinell $\left(\mathrm{kgf} / \mathbf{m m}^{\mathbf{2}}\right)$

$\mathrm{P}=$ Beban yang diberikan (Kgf).

$\pi=3,14$

$\mathrm{D}=$ Diameter indentor yang digunakan (mm)

$\mathrm{d}=$ Diameter bekas lekukan (mm).

\section{Struktur Mikro}

Pengamatan struktur mikro dilakukan dengan alat yang sama yaitu dengan miskroskop logam optik. Pengamatan struktur mikro fokus pengamatan adalah distribusi perubahan struktur mikro pada tiap-tiap bagian sebagai akibat adanya siklus termal selama pengelasan. Metalografi dilakukan untuk melihat terjadinya perubahan struktur mikro pada objek penelitian sebagai akibat dari proses-proses eksperimen yang telah diterimanya. Pada spesimen normal dan tanah pasir dipotong dengan dimensi $10 \mathrm{~mm}$ x $\varnothing 8 \mathrm{~mm}$, kemudian dilakukan penyalutan (mounting), karena benda kerja yang kecil sukar untuk dipegang pada proses penggerindaan dan pemolesan, maka perlu disalut lebih dahulu. Sebagai penyalut digunakan bahan thermoplastik, seperti resin. Bahan penyalut ini mencair pada temperature $150^{\circ} \mathrm{C}$. 


\section{SANG PENCERAH}

Volume 2, Nomor 2, Agustus 2016, ISSN 2460-5697, Hlm. 39-44

Muhamad Iqbal Achmad: Sifat Mekanik Elektroda Batang Arde ...

\section{Pembahasan}

Hasil analisis perhitungan untuk memperoleh nilai kekerasan dari specimen tanpa pembumian sebagai berikut.

Data:

$\mathrm{P}=60 \mathrm{~kg} \pi=3,14$

$\mathrm{D}=1.588 \mathrm{~mm} \quad \mathrm{~d}=0.65 \mathrm{~mm}$

$$
\begin{gathered}
H B=\frac{2 P}{\pi D\left(D-\sqrt{D^{2}-d^{2}}\right.} \\
=\frac{2.60}{3.14 \times 1.588\left(1.588-\sqrt{1.588^{2}-0.65^{2}}\right.} \\
=\frac{120}{4.98632(1.588-\sqrt{2.09924)}} \\
=\frac{120}{4.98632(1.588-1.44887)} \\
=\frac{120}{4.98632 \times 0.13912} \\
=174 \mathrm{kgf} / \mathrm{mm} 2
\end{gathered}
$$

\begin{tabular}{|c|c|c|c|c|c|c|c|}
\hline \multicolumn{2}{|l|}{ Spesimen } & \multirow{2}{*}{$\begin{array}{c}\mathbf{P} \\
\text { Load } \\
(\mathbf{K g})\end{array}$} & \multirow{2}{*}{$\begin{array}{c}\begin{array}{c}\mathrm{D} \\
(\mathbf{m m})\end{array} \\
1,588\end{array}$} & \multicolumn{2}{|c|}{$\mathrm{d}(\mathrm{mm})$} & \multirow{2}{*}{$\begin{array}{c}\text { HB } \\
\text { (Kg/m } \\
\text { m2) } \\
145,40\end{array}$} & \multirow[t]{2}{*}{ Rerata } \\
\hline \multirow{3}{*}{$\begin{array}{l}\text { Tanpa } \\
\text { Pembumian }\end{array}$} & 1 & & & 24 & 0,71 & & \\
\hline & 2 & 60 & 1,588 & 23 & 0,68 & 159,07 & \multirow[t]{2}{*}{159,70} \\
\hline & 3 & 60 & 1,588 & 22 & 0,65 & 174,63 & \\
\hline \multirow{3}{*}{$\begin{array}{l}\text { Pembumian } \\
\text { dengan Tanah } \\
\text { Pasir }\end{array}$} & 1 & 60 & 1,588 & 25 & 0,74 & 133,34 & \multirow{3}{*}{129,77} \\
\hline & 2 & 60 & 1,588 & 26 & 0,76 & 122,63 & \\
\hline & 3 & 60 & 1,588 & 25 & 0,74 & 133,34 & \\
\hline
\end{tabular}

Tabel 3 Hasil Pengujian Kekerasan Brinell (Hbn) Untuk Elektroda Batang Arde Tanpa Melalui Pembumian dan Pembumian Dengan Pasir Tanah.

\section{Hasil Pengujian Kekerasan Vs Elektroda Batang Arde}

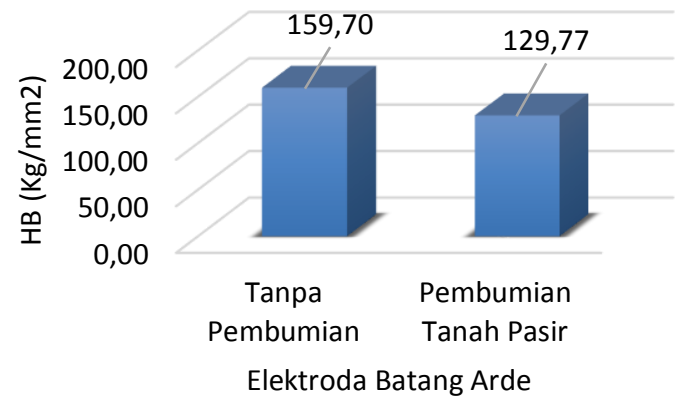

Gambar 1 Grafik Hubungan Antara Hasil Pengujian Kekerasan (HBN) Terhadap Specimen Elektroda Batang Arde Tanpa Pembumian dan Pembumian Dengan Tanah Pasir

Melalui pengamatan tabel uji kekerasan tabel 1 dan gambar 1, dapat dilihat bahwa specimen tanpa pembumian mempunyai nilai kekerasan $(\mathrm{HBN})$ sebesar $159,70 \mathrm{kgf} / \mathrm{mm}^{2}$, dan setelah dilakukan proses pembumian di lokasi tanah berpasir dengan nilai uji kekerasannya sebesar $129,77 \mathrm{kgf} / \mathrm{mm}^{2}$. Pada lokasi tanah berpasir terjadi penurunan nilai kekerasan dari nilai kekerasan tanpa pembumian. Ini di sebabkan karena lokasi tempat pembumian mempunyai kadar garam dan tingkat korosi yang paling tinggi (lihat tabel 1 dan tabel 2).

\section{Struktur Mikro Tanpa Pembumian}

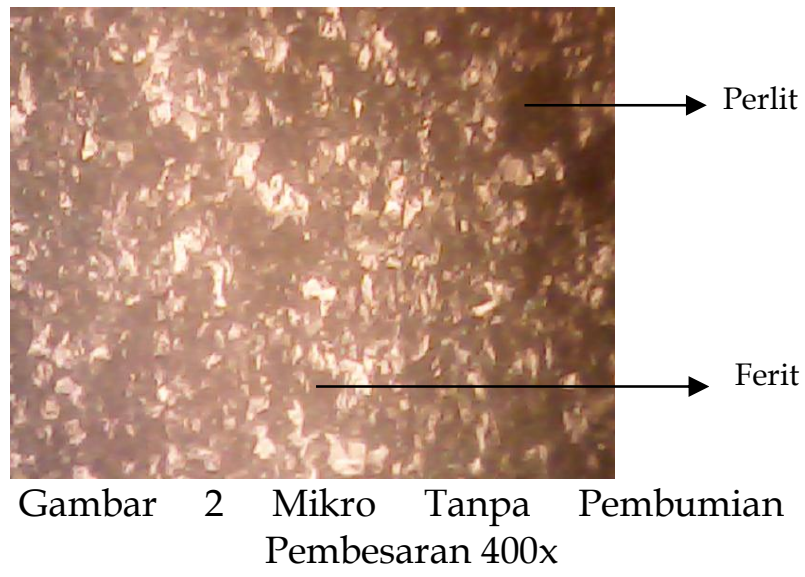




\section{SANG PENCERAH}

Volume 2, Nomor 2, Agustus 2016, ISSN 2460-5697, Hlm. 39-44

Muhamad Iqbal Achmad: Sifat Mekanik Elektroda Batang Arde ...

Pada gambar 2 terlihat struktur mikro Elektroda batang Arde sebelum di lakukan proses pembumian. Struktur mikro yang tebentuk adalah fase ferit dan fase perlit, dimana struktur ferit berwarna terang, fase ini mempunyai sifat yang lunak dan perlit yang berwarna gelap mempunyai sifat yang keras tergantung pada kandungan karbonnya.

\section{Struktur Mikro di Tanah Berpasir}

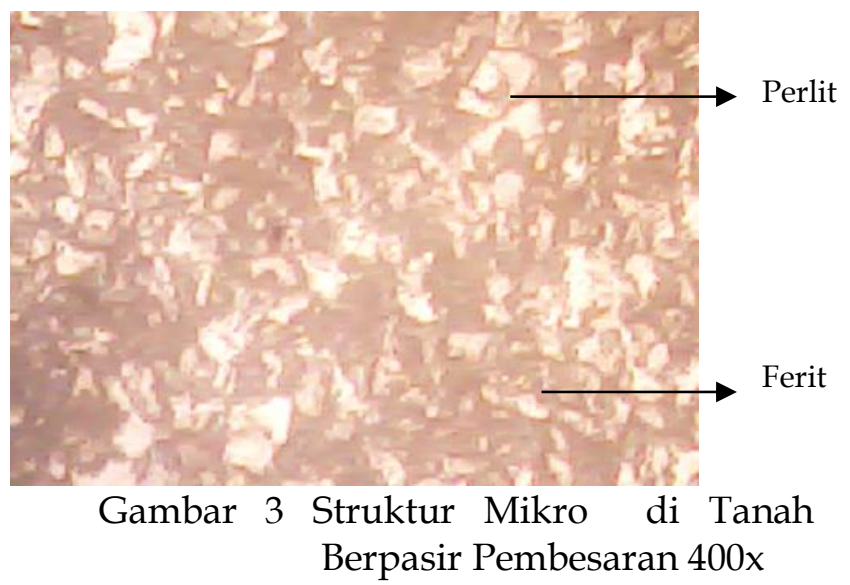

Pada gambar 3 terlihat struktur mikro elektroda batang arde setelah melalui proses pembumian di lokasi tanah berpasir. Struktur mikro yang tebentuk adalah fase perlit yang berwarna gelap mulai tampak samar dan berkurang. Sedangkan fase ferit yang berwarna terang semakin melebar dan mengikat satu sama lain lebih mendominasi pada struktur tersebut. struktur ferlit yang seragam bersifat lunak serta dibuktikan dengan menurunnya nilai kekerasannya.

\section{Simpulan}

Simpulan penelitian ini bahwa tempat pembumian elektroda batang arde terpasang akan terjadi proses korosi, pada lokasi tempat pembumian tersebut dan semakin tinggi tingkat korosi pada lokasi dimana batang Arde terpasang maka akan semakin besar pula penurunan nilai kekerasannya yaitu, pada lokasi tanah berpasir 129,77 $\mathrm{kgf} / \mathrm{mm}^{2}$ dan struktur mikro yang terjadi cenderung berubah dari fase perlit yang bersifat keras ke fase ferit yang bersifat lunak lebih mendominasi pada setiap strukturnya.

\section{Daftar Pustaka}

Avner, S.H. 1964. Introduction to Physical Metallurgy. New York: Mc. Graw-Hill.

Baumer, B.M.J. 1994. Ilmu Bahan Logam. Jakarta: Bhratara.

Bradbury. 1997. Dasar Metalurgi Untuk Rekasasawan. Jakarta: PT Gramedia Pustaka Utama.

Djaprie, Sriati. 1992. Teknologi Mekanik jilid 1. Jakarta: Erlangga.

2000. Metalurgi Fisik Modern dan Rekayasa Material Edisi Keenam. Jakarta: Erlangga.

Koswara, Engkos. 1999. Pengujian Logam. Bandung: Humaniora Utama Press Bandung.

Lawrence H. Van Vlack. 1991. Ilmu dan Teknologi Bahan edisi Kelima. Jakarta: Erlangga.

Susangka, Dwi. Laporan Praktikum Metalurgi FT. UNHAS 2013.

ThetheWeY, K.R. and Chamberlain J. 1991.Korosi untuk Mahasiswa dan Rekayasawan. Jakarta: Gramedia. 


\section{SANG PENCERAH}

Volume 2, Nomor 2, Agustus 2016, ISSN 2460-5697, Hlm. 39-44

Muhamad Iqbal Achmad: Sifat Mekanik Elektroda Batang Arde ...

http://m10mechanicalengineering.blogspot.co

$\mathrm{m} / 2013 / 11 /$ macam-macam-bentuk-

korosi.html (diakses 15 November 2014)

http://fasdilahali.blogspot.com/2012/05/pepti

da-dan-ikatan peptida.html (diakses 15

November 2014).

http://ners-

septian.blogspot.com/2012/09/korosi.html

(diakses 16 November 2014)

http://digilib.unimus.ac.id/files/disk1/119/jt

ptunimus-gdl-muhamatyas-5924-3-babii.pdf

(diakses 18 November 2014)

http://sistimlistrikaliranatas.blogspot.com/201

2/11/v-behaviorurldefaultvmlo.html (diakses

20 November 2014)

http://arikusmanto.blogspot.com/2013/09/pe

ntanahan.html (diakses 23 November 2014)

http://ratihkumalachachae.blogspot.com/2011

L12/mengenal-korosi-dan-akibatnya-serta.html (diakses 25 November 2014) 